\title{
SURGICAL TREATMENT OF MALE INFERTILITY
}

(Received 6 June, 1994)

\section{i. Alkan, M.D.*** / L. Türkeri, M.D.** / F. șimșek, M.D.* / A. Akdaș, M.D.*}

\footnotetext{
- Professor, Department of Urology, Faculty of Medicine, Marmara University, Istanbul, Turkey.

* Assistant Professor, Department of Urology, Faculty of Medicine, Marmara University, Istanbul, Turkey

-.. Resident, Department of Urology, Faculty of Medicine, Marmara University, Istanbul, Turkey.
}

\section{SUMMARY}

The male partner is the reason for infertility in about $50 \%$ of childless marriages. New surgical and reproductive technologic improvements have expanded the horizon of male infertility surgery. Recent advances in microsurgical techniques applied to male infertility will be discussed.

Key Words : Male infertility, surgery

\section{INTRODUCTION}

Approximately $8 \%$ to $10 \%$ of all couples have impaired fertility. $(1,2)$. The prevalence of infertility increases with age, and the percentage of couples with infertility in 35 to 44 year old group reaches up to $21 \%$ (1). Male factor infertility is either the sole cause or a contributing factor in $50 \%$ of infertile couples (3).

Most of the recent highlights in the area of male reproductive surgery involve the use of operating microscope. Microsurgery for the correction of duct obstruction became popular after Silber and Owen published their separate reports in the $1970(4,5)$. They documented high patency and pregnancy rates achieved through the reapproximation of the ends of the vas deferens in men who had previously undergone vasectomy $(4,5)$. Other than vasectomy reversal, the urologist has found microsurgical techniques useful for vasoepididymostomy, varicocele ligation, epididymal aspiration, placement of alloplastic spermatocele, testicular autotransplantation and various other procedures.

The male factor in infertility can be classified as; (1) pretesticular, relating to the causes of oligoasthenospermia or azoospermia to insufficient endocrine stimulus of a congenital or acquired nature, (2) testicular, regarding to anatomic and histologic abnormalities in the setting of normal hormonal response, (3) posttesticular, obstruction that represents $10 \%-15 \%$ of male infertility problems. In this group, normal spermatogenesis is present, but there is obstruction of ducts from either a congenital or acquired cause. It is this group of men in whom microsurgical intervention is benefical. (6).

\section{EVALUATION OF THE AZOOSPERMIC MAN}

In evaluation of the man, at least two semen analysis are required with a 2 to 4 week interval. Each specimen is obtained 3 days after ejaculatory abstinence. If no sperm are found and the semen volume is less than $1.5 \mathrm{ml}$, a postejaculatory urine analysis is necessary to rule out retrograde ejaculation. Fig. 1 presents an algorithm for evaluation of azoospermia (6).

Ductal obstruction may be due to congenital or acquired etiologies. Congenital mesonephric duct abnormalities may result in obstruction of excurrent ducts. Complete vasal agenesis is the most common abnormality (7) and the most common upper urinary tract abnormality associated with vasal agenesis is renal agenesis (8). Obstruction of excurrent ductal system may also be acquired during adulthood. Inflammatory lesions were the most common cause of the acquired ductal obstruction in the past. Venereal disease and GU Tuberculosis were the leading etiologies of obstructive azoospermia (9). However, modern antibiotic treatment has reduced the incidence of this complication. Today, the most frequent casue of acquired ductal obstruction is iatrogenic (9). Prior inguinal or scrotal surgery may result inadvertent injury to the vas deferens or epididymis. Transurethral endoscopic procedures may result in ejaculatory duct obstruction. The association of chronic sinusitis, bronchiectasis, and azoospermia characterize Young's syndrome (10). The azoospermia in Young's syndrome is due to obstruction of epididymis by inspissated secretions. The exact cause of this disorder is unknown.

When the vasa deterentia or epıdidymis are obstructed, the patient's semen is alkaline and the volume of fluid normal $(1,5-5 \mathrm{ml})$. Fructose is present in the semen in normal quantities. $(>150 \mathrm{mg} / \mathrm{d}$ ) $)$. In contrast, if the obstruction is at the level of ejaculatory ducts, the semen volume is small $(<1 \mathrm{ml})$, with little or no fructose present, and the ejaculate is acidic from prostate secretions (9). 
The surgical treatment of male infertility consists largerly of two types of operations:

1) varicocele repair, 2) treatment of obstructive azoospermia.

It is the latter category which is the subject of this review.

\section{TREATMENT OF OBSTRUCTIVE AZOOSPERMIA}

A) Vasectomy reversal

B) Vasoepididymostomy

C) Treatment of obstruction not caused by vasectomy

I) Inguinal disruption of vas deferens after herniorrhaphy

II) Ejaculatory duct obstruction

III) Congenital absence of vas deferens.

\section{A) VASECTOMY REVERSAL (UASOVASOSTOMY)}

Vasectomy is the most common cause of obstructive azoospermia in western countries. In 1919 Quinby reported a successful anastomosis of the vas deferens after vasectomy (11). Experienced microsurgeon using operating microscope, achieved consistently higher patency and pregnancy rates when compared to their colleagues who did not utilize this method (Table 1).

These results and other reports show that microsurgical techniques have more promising results. Determination of the level of the obstruction is made at the time of scrotal exploration. Vasography determines patency of the distal vas and the ejaculatory ducts. Microscopic examination of the vasal fluid determines patency of the proximal vas and epididymis by the presence of sperm in the vasal fluid. The presence of intravasal azoospermia indicates epididymal obstruction if the patient has documented sperm production in the testis. The information gained by microscopic characterization of the sperm in the vasal fluid allows extremely accurate prediction of success or failure after properly performed vasovasostomy. and establishes the likelihood of secondary epididymal blockage (13). The absence of sperm in the vasal fluid is usually due to epididymal rupture and secondary blockage. If the level of obstruction is not readily apparent, stepwise transection starting on the convoluted vas should be carried out until the fluid reveals sperm.

The motility of sperm in the obstructed segment has no effect on prognosis (13-15). Therefore, this finding suggests that vasoepididymostomy should be performed at the lowest level in the epididymis at which sperm and good flow are found, regardless of motility (15).

Another consideration in vasectomy reversal is the increased incidence over time of secondary epididymal 'blowout'. Since the sperm production continued by the testis, sperm travels through the obstructed proximal excurrent system, and pressure induced extravasation may occur anywhere in the epididymal tubule. This results in a local inflammatory reaction that blocks the passage of the sperm. If this situation is recognized at the time of vasectomy reversal, vasoepididymostomy is required.

The success rate of vasovasostomy is very high. Without concomitant epididymal obstruction, the result are similar to that of vasectomy reversal. Average patency rates are $70 \%$ to $90 \%$ and pregnancy rates are $80 \%$ to $50 \%$ (14). However, duration of obstruction is an important factor for pregnancy rate (10) (Fig. 2).

Technique: Microsurgical anastomosis is better than macrosurgery $(6,10)$. Microsurgical vasovasostomy, whether to reverse a vasectomy or to correct another cause of vasal obstruction, may be performed with equal success using either modified single or double layer anastomosis $(6,14)$. The operating microscope permits more precise apposition of the mucosal edges, and minimizes the possibility of sperm extravasation, a potential cause of operative failure (16). A splint of any kind should never be used, because it results in sperm leakage, inflammation, and increased scarring (13).

Microsurgical Techniques can be utilized by operating microscopes that provide magnification from 6 to 32 times.

\section{B) VASOEPIDIDYMOSTOMY}

With the aid of the operating microscope, success rate is high. Silber (17) has described a technique of end-to-end anastomosis of the vas deferens to the open end of a single, patent epididymal tubule. His results were reportedly superior to those previously described in the literature. A modification of this technique has also been described (18-20). This method consists of end-to-side anastomosis of the lumen of the vas deferens to an opening at the side of the epididymal tubule, above the level of obstruction. Patency and pregnancy rates of microsurgical vasoepididymostomies are presented in table II $(17,19,20,21)$.

Although, the epididymis has an important role in achievement of sperm motility and fertilizing capacity, in obstructed systems sperm can acquire motility and fertilizing capacity with little or no exposure to the epididymal environment. Niederberg and Ross showed that the best predictor of successful microsurgical vasoepididymostomy is the presence of sperm in the epididymal fluid (15). Authors found that the presence of motile or non-motile sperm in the epididymal fluid was not a significant predictor of success (15). This important finding suggests that vasoepididymostomy should be performed at the lowest end of the epididymis where good sperm count and flow is found, regardless of motility $(15,17,20)$. 
The issue of end-to-end versus end-to-side anastomosis is probably not important

\section{C) TREATMENT OF OBSTRUCTION NOT CAUSED BY VASECTOMY}

\section{1) Inguinal disruption of vas deferens affer herniorraphy}

Bilateral herniorraphy, specially in infancy, carries a high risk of causing iatrogenic obstruction of vas deferens (13). Such patients generally complain of infertility in young adulthood.

The vasogram shows that vas deferens are obstructed at the level of external or internal inguinal ring on both sides. It can be difficult to anastomose the vas deferens due to long segmental loss. Furthermore, there is usually existing secondary epididymal blockage which requires a vasoepididymostomy (13).
Bilateral infant herniorraphy may probably sterilize about $2 \%$ of children. These unsettling figures argue strongly for using ocular loops more routinely for certain pediatric procedures including herniorraphy (13).

\section{II) Ejaculatory duct obstruction}

A rare cause of azoospermia is congenital obstruction of the ejaculatory duct $(22,23)$. This diagnosis is made when the patient has a palpable vas deferens, azoospermia, and a normal testicle biopsy, in the presence of low ejaculate volume with no fructose. Ejaculatory duct obstruction is usually detected by transrectal ultrasonography in patients with low semen volume.

These patients should be treated by transurethral incision of the ejaculatory ducts $(22,23)$. This is performed using Colling's knife or resecting loop with pure cutting current. The posterior aspect of the prostatic urethra is incised just proximal to and

\section{AZOOSPERMIA}

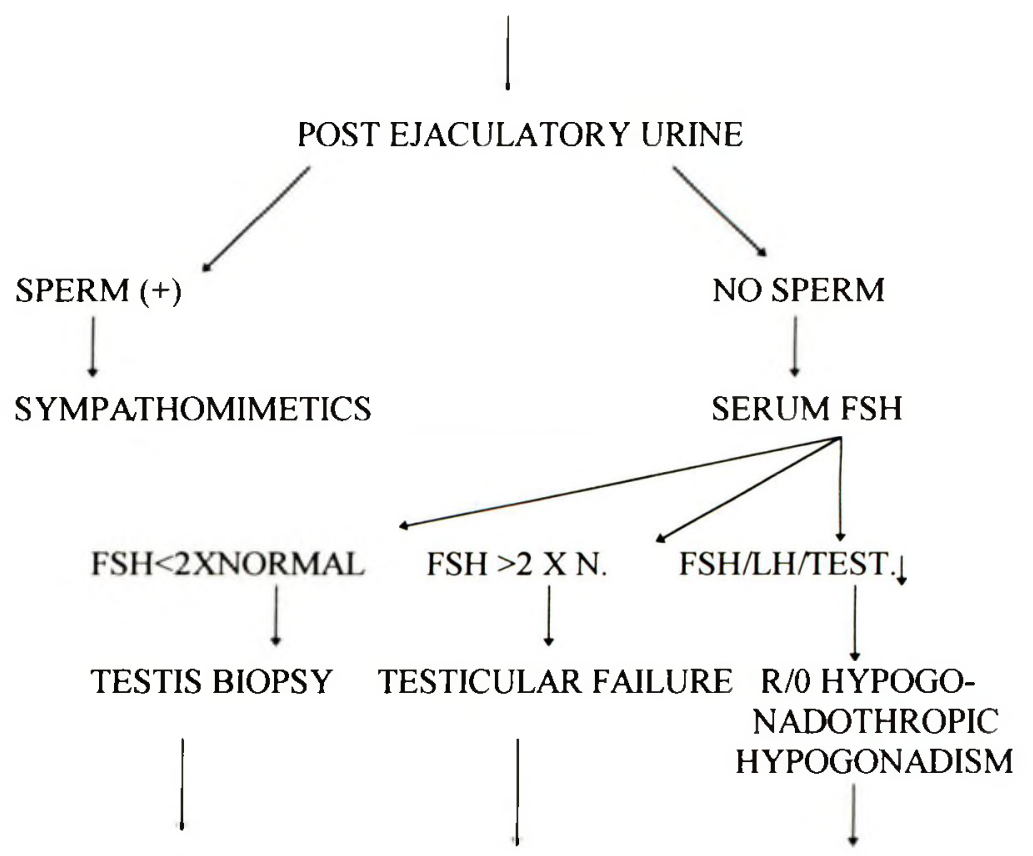

NORMAL

SPERMATOGENESIS NO TREATMENT

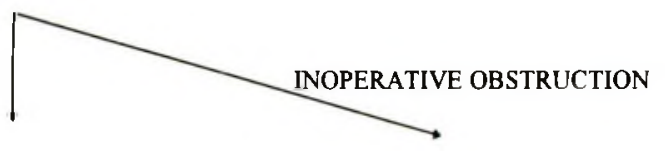

HORMONAL THERAPY
Fig 1. Evaluation of azoospermic patients 


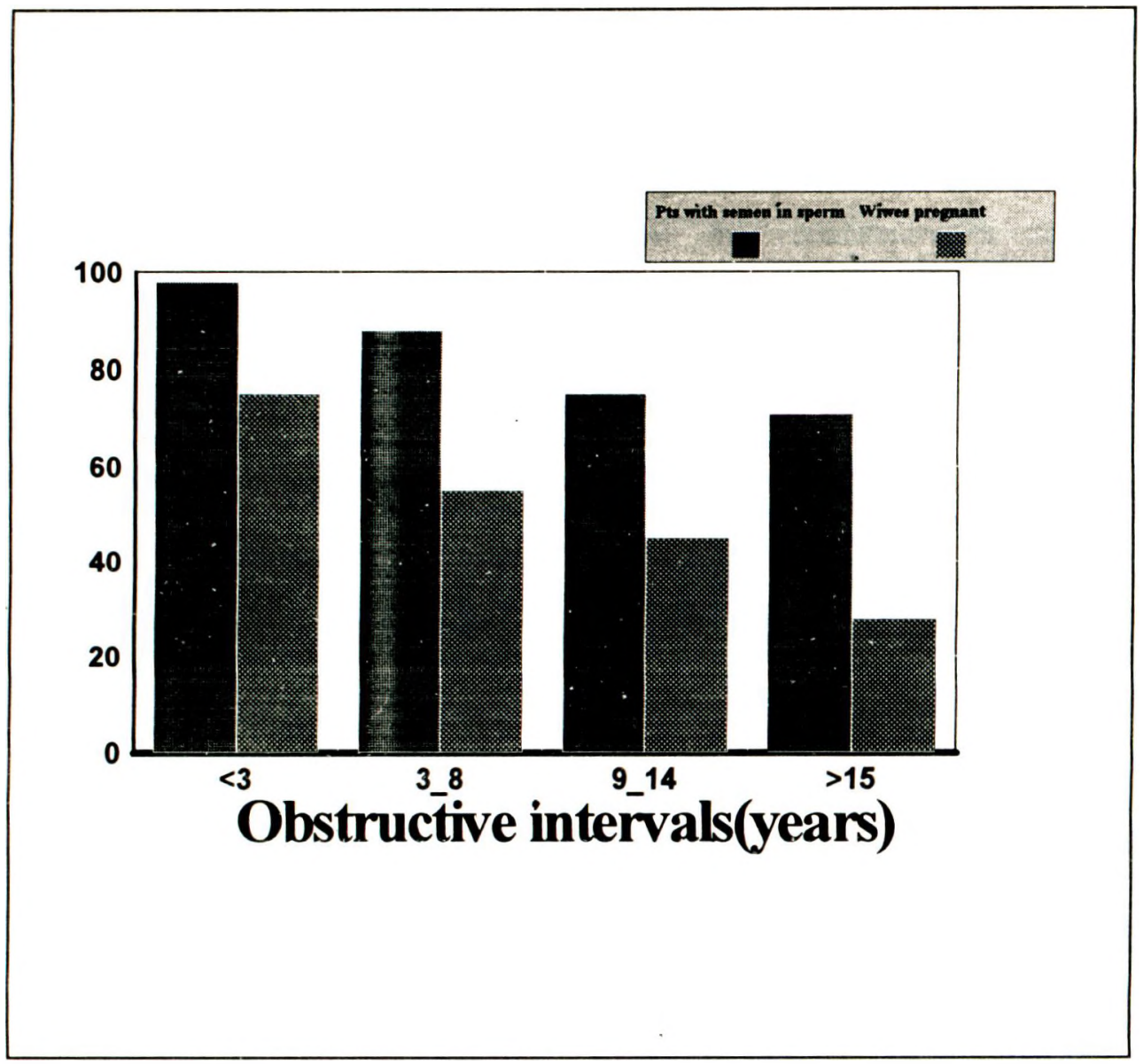

Fig 2. (From Belker A.E. et. al. Results of 1469 microsurgical vasectomy reversals by The Vasovasostomy Study Group. J. Urol. 145:505,1991)

slightly lateral to the veru - montanum $(22,23)$. Incision should not extend up to the bladder neck or distal to the veru. The incision is complete when seminal secretions are visualized. Follow-up in these patients consists of repeated semen analyses. Persistent ejaculatory duct obstruction should be suspected if the seminal volume remains low. However, persistent azoospermia with normalization of ejaculate volume indicates presence of more proximal obstruction usually at the level of the epididymis. Without epididymal obstruction the prognosis for fertility in patients appears to be excellent.

\section{III) Vasal Agenesis}

Congenital absence of both vas deferens accounts for approximately $10 \%$ of cases of obstructive azoospermia.

Until recently, alloplastic spermatocel is used to treat bilateral vasal agenesis, but this procedure is unsuccessful because of two reasons: There is a high rate of stricture formation at the site of epididymal anastomosis, and the quality of sperm aspirated from his reservoirs is extremely poor (24).
A relatively new technique, epididymal sperm aspiration has more promising results. First human pregnancy resulting from microsurgical aspirations of sperm from the epididymis and in-vitro fertilization was reported by Temple and Smith et. al. in a patient with failed vasoepididymostomy (25). Silber et. al. extended these techniques to men with congenital absence of vas deferens (26).

The operating microscope is required for visualization of the epididymal tubule, and aspiration of sperm directly from the epididymis using a simple cannula. This sperm can then be used for in-vitro fertilization on other reproductive technology protocols and Silber et. al. have reported live birth rates as high as $20 \%$ using this technique (26-28).

In conclusion, the application of advanced microsurgical techniques have greatly enhanced the ability of the urologist to treat the azoospermic men who are found to have surgically correctable problems. This new area of technical advances requires, urologists to be aware of the new assisted reproductive techniques, and understand the importance of team work with reproductive endocrinologists. 
Table I

\begin{tabular}{|c|c|c|c|c|}
\hline \multicolumn{5}{|c|}{ MICROSURGERY } \\
\hline AUTHOR & YEAR & $\begin{array}{c}\text { NO OF } \\
\text { PATIENTS }\end{array}$ & $\begin{array}{c}\% \text { WITH } \\
\text { SPERM }\end{array}$ & $\begin{array}{c}\% \\
\text { PREGNANCIES }\end{array}$ \\
\hline OWEN & 1977 & 50 & 98 & 72 \\
\hline SILBER & 1978 & 126 & 90 & 76 \\
\hline SHARLIP & 1978 & 17 & 76 & 47 \\
\hline THOMAS & 1981 & 55 & 89 & 55 \\
\hline KAYE ET AL & 1983 & 25 & 95 & - \\
\hline REQUEDA & 1983 & 47 & 80 & 46 \\
\hline $\begin{array}{c}\text { MC CLURE } \\
\text { SHY }\end{array}$ & 1986 & 50 & 90 & 52 \\
\hline $\begin{array}{c}\text { M G STUDY } \\
\text { GROUP }\end{array}$ & 1991 & 1247 & 86 & \\
\hline
\end{tabular}

\begin{tabular}{|c|c|c|c|c|}
\hline \multicolumn{5}{|c|}{ MACROSURGERY } \\
\hline DERRICK & 1973 & 1,630 & 38 & 19 \\
\hline SCHMIDT & 1975 & 45 & $80-90$ & 45 \\
\hline AMELAR & 1975 & 93 & 84 & 33 \\
\hline MIDDLETON & 1978 & 72 & 95 & 39 \\
\hline LEE & 1978 & 222 & 82 & 34 \\
\hline FALLON & 1978 & 41 & 83 & 40 \\
\hline
\end{tabular}

Table II. Microsurgical vasoepididymostomy. (tubule - to - tubule anastomosis)

\begin{tabular}{|c|c|c|c|c|}
\hline AUTHOR & YEAR & $\begin{array}{c}\text { NO. OF } \\
\text { PATIENT }\end{array}$ & $\begin{array}{c}\text { NO. WITH } \\
\text { SPERM (\%) }\end{array}$ & $\begin{array}{c}\text { NO. OF } \\
\text { PREGNANCIES }\end{array}$ \\
\hline SILBER & 1978 & 14 & $12(86)$ & - \\
\hline MCLOUGHLIN & 1982 & 23 & - & $9(39)$ \\
\hline UUBIN AND AMELAH & 1984 & 46 & $18(39)$ & $6(13)$ \\
\hline BELGRANO ET AL & 1984 & 4 & $4(100)$ & $1(25)$ \\
\hline WAGENKNECT & 1985 & 50 & - & $12(23)$ \\
\hline FOGDESTAM & 1986 & 41 & $35(85)$ & $15(37)$ \\
\hline THOMAS & 1988 & 69 & $56(81)$ & $25(36)$ \\
\hline SILBER & 1989 & 139 & $(78)$ & $(56)$ \\
\hline
\end{tabular}




\section{REFERENCES}

1. Mosher WD, Pratt WF. Fecundity and infertility in the U.S.: Incidence and trends. Fertil Steril 1991;56:192-193.

2. Greenhall $E$, Vessey $M$. The prevalence of subfertility: A review of the current confusion and a report of two new studies. Fertil Steril 1990:54:978-983.

3. MacLeod J. Human Male Infertility: Obstet Gynecol Surv 1948;12:325-328.

4. Owen ER. Microsurgical vasovasostomy: A reliable vasectomy reversal. Aust NZS Surg 1977;47:305. 309.

5. Silber JS. Microsurgery in clinical urology. Urology 1975:6: 1.50-153.

6. Randall $M$. Microsurgery in male infertility. Infert. and Reproduct Medicine Clinics of North America 1992:3 (2) 444-452

7. Jarow JP. Evaluation of the azoospermic patients. J Urol 1989; 142: 62-65.

8. Donohue $R E$. Unilateral absence of vas deferens: A useful clinical sign. JAMA 1989;261:1180. 1182

9. Jonathan PJ. Current problems in urology. $1992: 2$ (1) $10-12$.

10. Young $D$. surgical treatment of male infertility. $J$ Reprod Fertil 1970; 23:54 I-542.

11. OConor VJ. Anastomosis of vas deferens after purposeful division for sterility. JAMA 1948;136:162-164.

12. Sharlip ID. Vasovasostomy and patency rate. Urology. 1978;11:315-316.

13. Silber JS. Surgical treatment of male infertility. Connecticut: Appleton and Lange 1990:169-183.

14. Belker AM, Thomas AJ, Fuchs EF. Results of 1469 microsurgical vasectomy reversal. J Urol 199I: 145:505-5II.

15. Niederberger C, Ross LS. Microsurgical vasoepididymostomy : Predictors of success. J Urol 1993:149:1364-1367.
16. Hagan K, Coffey DS. The adverse effects of sperm during vasovasostomy. J Urol 1977; 1 18:269-273.

17. Silber JS. Microscopic vasoepididymostomy. Fertil Steril 1978;30:565-567.

18. Thomas AJ. Vasoepididymostomy. Male Infertility. Urol Clin North Am 1987;14:527-530.

19. Dubin L, Richard A. Magnified surgery for vasoepididymostomy. Urology 1984;23:525-528.

20. Fogdestam I, Magnus F, Stig $N$. Microsurgical vasoepididymostomy in the treatment of obstructive azoospemia. Fertil Steril 1986:46:925-928.

21. Wagenknecht LV. Ten years experience with microsurgical vasoepididymostomy. $J$ Androl 1985;6:25-30.

22. Weintraub CM. Transurethral drainage of the seminal tract for obstruction infection, and infertility. $\mathrm{Br} J$ Urol 1980;52:220-223.

23. Carcon CC. Transurethral resection for ejaculatory duct stenosis and oligoospermia. Fertil Steril $1984 ; 41: 482-484$.

24. Turner TT. On the development and use of alloplastic spermatoceles. Fertil steril 1988:49:387-394.

25. Temple - Smith PD, Southwick GJ, Yates CA, Traunson AO. Kretser DM. Muman pregnancy by IVF using sperm aspirated from the epididymis. I In Vitro Fent Embryo Trans 1985;2:119-221.

26. Silber JS, Balmaceda J, Borrero C, Ord T, Asch R. Pregnancy with sperm aspiration from the proximal head of the epididymis. Fertil Steril I $988 ; 50$ (3) 525-528

27. Siber JS, Lord J, Marello E, Patrizio P. Congenital absence of vas deferens. $N$ Eng $J$ Med 1990;323: $1788-1792$.

28. Marmar JL, Stephan LC, Frances RB, Benjamin G. Microsurgical aspiration of sperm from the epididymis: A mobile program. J Urol 1993:149:1368-1373 